\title{
A NEW APPARATUS FOR THE COLLECTION OF BOTTOM PLANKTON
}

\author{
By J. Wickstead \\ From the Plymouth Laboratory
}

(Text-figs. I-5)

\section{INTRODUCTION}

Many workers have studied the vertical migrations of planktonic animals, and much knowledge has been gained of distribution at different levels at different times of the day. However, with the apparatus used by most of these workers, the plankton in the immediate vicinity of the sea-bottom has had to be neglected.

To sample this bottom plankton, various methods have been devised. Hensen (I895, Plates X and XI) designed a Wagennetz which was very complicated, and can have been of little practical use. Russell (I928), Reighard (I894), Beauchamp (1932) and Hardy \& Lucas (personal communication) each designed simple and effective nets, but these have the very serious disadvantage of not limiting the samples to the bottom, and there is no way of telling at what level any particular specimen was collected.

The apparatus of Greze (I95I) has apparently only been used in inland waters, its effectiveness in the sea being a matter of speculation. Here, precise workmanship is involved, and a finely adjusted mechanism. The latter is to be avoided if possible, since dragging along the sea-bed can so very easily disturb its accurate functioning.

The apparatus used by Bossanyi (I95I) effectively restricts the haul to the bottom, but has some disadvantages, i.e. it is heavy and cumbersome, and can be used only in reasonably calm waters and in limited areas where the bottom deposit is suitable.

The apparatus about to be described has been devised to overcome these limitations. It is successful in that it is capable of sampling bottom plankton only; easy to handle, weighing only about $90 \mathrm{lb}$.; easy to shoot, the shooting not necessarily being restricted to calm weather; simple mechanically; independent of the sea-bed for operating; and self-contained, dispensing with messengers and throttling nooses; and it can be used for making accurately timed hauls.

The principles involved in the working are quite different from those of Bossanyi's net. The idea of using water pressure created over a plane surface caused by towing is not entirely new: Giesbrecht (I893) used it for a mid-water 
closing net. However, it does not seem to have been used since, certainly not for a bottom plankton net.

I am very much indebted to $\mathrm{Mr}$ J. M. Smith, of University College, London; to Captain C. A. Hoodless, D.S.C., and the crew of R.V. Sabella; to the Plymouth Corporation, for permission to use their open-air swimming bath; and to Mr P. G. Corbin, whose suggestions and criticisms throughout have been invaluable.

The work was carried out at the Plymouth Laboratory while holding a Colonial Office Studentship.

\section{DESCRIPTION}

The apparatus consists of a net, with locks, etc., supported on a rectangular base, $5 \mathrm{ft} .3$ in. by $3 \mathrm{ft}$. 7 in., and mounted on runners. The runners raise the net some 8 in. above the ground (Fig. I C).

At the anterior part of the net is a box of thin sheet iron, 24 in. wide, 15 in. high, and $\mathrm{I}_{2}$ in. deep. A 4 in. bucket fits into the cod-end of the net proper. A hinged brass band secures the cod-end to the bucket, and the bucket is attached to the frame by a stout cord.

The net-box is central to the width of the frame, and is flush with the front cross-bar. (Attachment by bolting is used throughout to facilitate such alterations that may have been necessary.) The top of the net-box is supported by two steel strips, bent as seen in Fig. I B, leaving a 3 -in. gap between the sides of the net-box and uprights of the supports. The back 2 in. of the box is kept free of the supports for fitting of the net proper.

The bearings for the door-hinge are two $\frac{1}{2}$ in. holes in the anterior support, the centre of each hole being Io in. from the top of the front cross-bar, and $I_{4}^{1}$ in. from the leading edge of the support. Straight $\frac{1}{2}$ in. brass tubing serves as the door hinge, held in place by a washer and split-pin at either end. Two slots are cut in the sides of the box to accommodate the hinge.

The door is a sheet of I6-gauge aluminium, $23 \frac{1}{2}$ in. by I $4 \frac{1}{2}$ in.; and is bolted directly to the hinge. When in position and closed, it leaves a gap of $\frac{1}{4}$ in. around the edge, and is about $\mathrm{I}_{2} \frac{1}{2}$ in. within the box (Fig. IC). It is braced behind by stout aluminium angle, a piece from each bottom corner to centre top, and a piece from centre top to centre bottom.

During trials with a small experimental model, it was found important to have the door attached behind the hinge.

Outside the net-box two stout levers are attached to the door hinge. From the centre of the diameter of the door hinge to the lever/connecting-arm hinge is $7 \frac{1}{2}$ in. About 4 in. of the levers are above the door hinge to act as a counterweight. When the door is vertical, the levers project forward at about $20^{\circ}$ from vertical (Fig. 2A). 


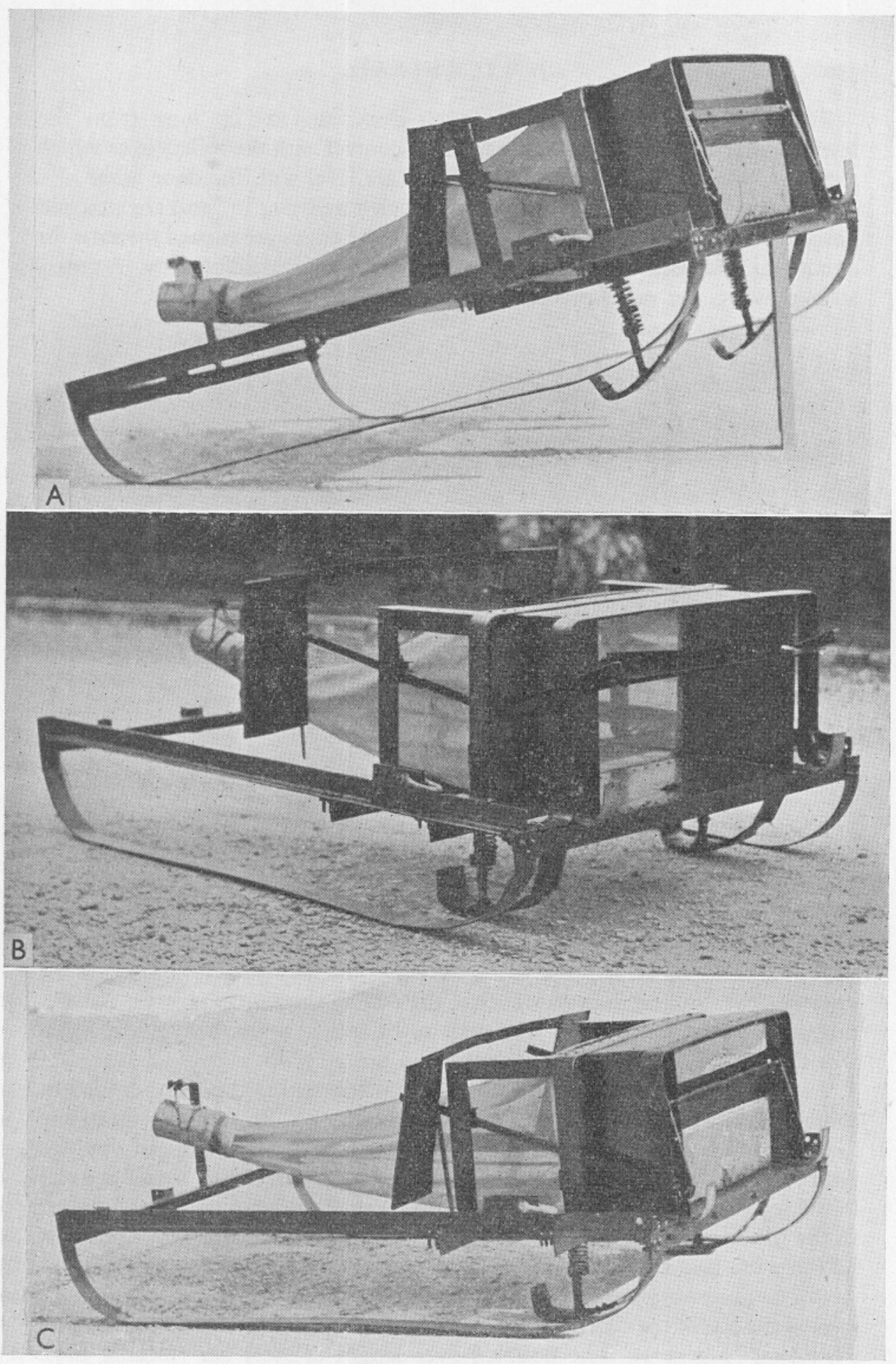

Fig. I. A, the apparatus locked for lowering to the bottom; B, the apparatus open, as it is towed along the bottom; c, the apparatus locked at the end of the haul and ready for bringing to the surface. 
The connecting-arms are $\frac{3}{4}$ in. angle-iron, each 25 in. long from the lever/connecting-arm hinge to the point of contact with the rollers over which they run (Fig. 2A). The tops of the rollers are level with the door hinge.

The vanes are of 16 -gauge aluminium, each 7 in. by 14 in., and are attached perpendicularly to the connecting-arms. All the edges are turned forward for about $\frac{1}{4}$ in. to increase turbulence, and thereby to increase efficiency. A crossstrut prevents the vanes pivoting laterally on the connecting-arms.

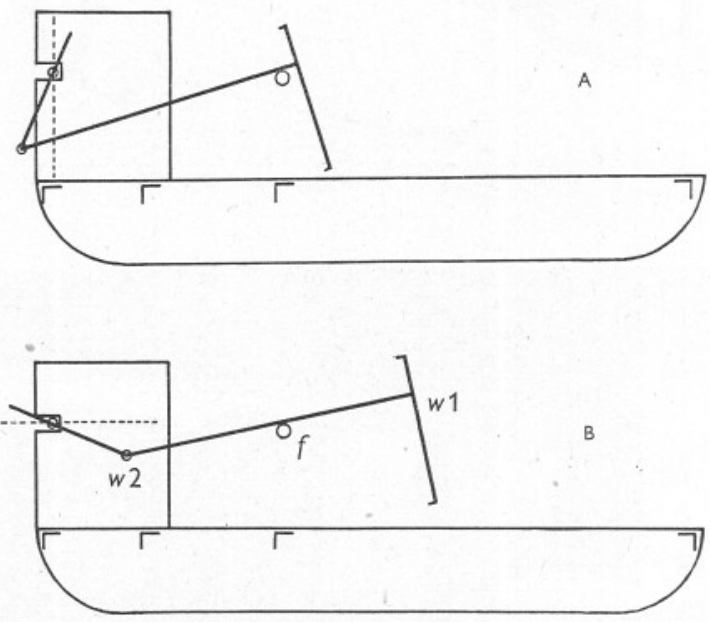

Fig. 2. Diagrammatic side-view of the net: A, closed; B, open. The dotted line represents the door. For explanation see text.

The principle of the apparatus is as follows. When towed through water, the pressure against the vanes and the lower part of the door pushes the vanes backwards. This pulls back the connecting-arms; the connecting-arms pull on the levers, causing the door hinge to rotate through $90^{\circ}$, thus opening the door (Fig. 2B). When stationary, the weight of the door plus levers causes the door to close, pulling the vanes back to the resting position (Fig. 2A). Attachments described below allow the door to be locked when lowered, to open when being hauled, and to be locked when bringing up.

Two small, thin sheet-metal, half-runners, attached to the front cross-bar, project some $2 \frac{1}{2}$ in. below the main runners (Fig. I A). Running up from, and hinged to, the free end of each half runner is a steel bar, bent and doubled back for about $2 \frac{1}{2}$ in. at the top (Fig. 3). Guiding the steel bars is an open slot in the second cross-bar, and a closed slot in a small piece of angle steel bolted to the inside of the upright of the posterior net-box support. The steel bars, between the half-runner hinges and the second cross-bar, act as cores to two strong compression springs (Fig. 3). Bolts through the steel bars act as stops against the top of the cross-bar when the springs are at almost their maximum expansion (Fig. 3, s). The doubled-over length of steel bar (locking bar). 
fits into a slotted piece of iron attached to each connecting arm when the spring expands. The connecting arms are thus locked with the door just sufficiently open to avoid the locking trips (Fig. IA).

When the net is being prepared for shooting, the small half-runners are raised, the door fully opened, two strips of metal inserted beside the con-

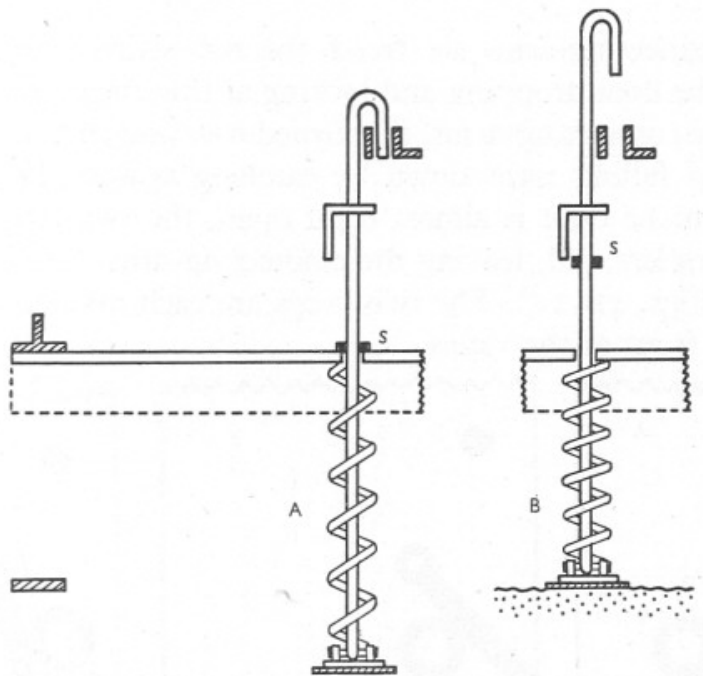

Fig. 3. Operation of the locking bar. For explanation see text.
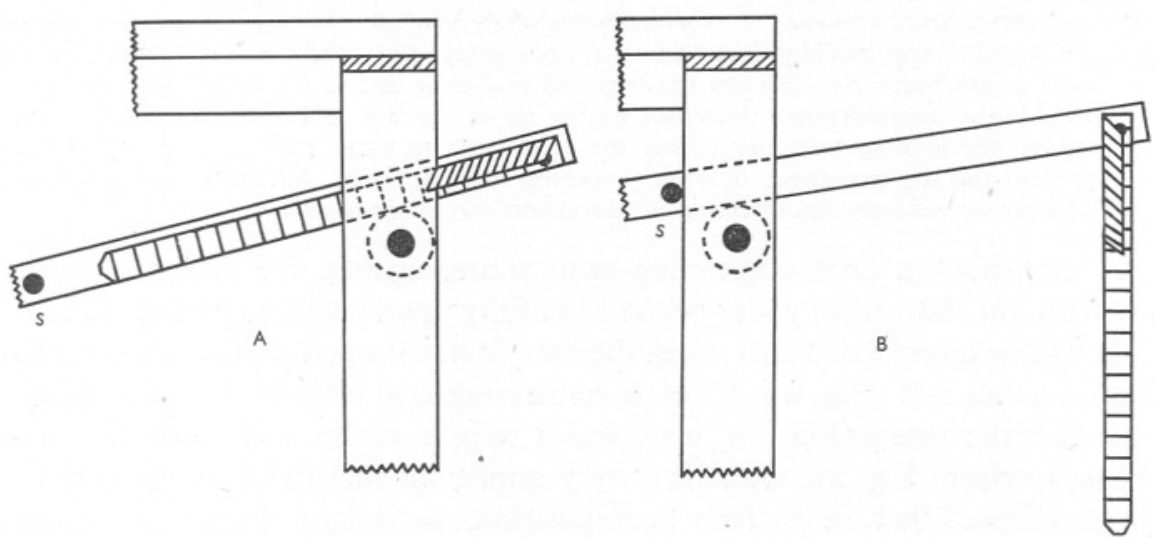

Fig. 4. Function of metal strips. For explanation see text.

necting-arms (see below), the door closed as far as possible, the small halfrunners released, the springs pulling the locking bars into the slotted pieces of iron (Fig. 3A). This action locks the connecting-arms, and therefore the door. The net is shot in this state (Fig. IA). On reaching the bottom, the whole weight of the apparatus rests upon the two small half-runners, com- 
pressing the springs until the main runners take the weight. This compression raises the locking bars, thus freeing the connecting-arms, enabling the door to open (Fig. 3B).

Over the bottom of the two small half-runners some fairly stout sheet metal is fixed, to act as 'rubber soles', and prevent the small half-runners from wearing out.

When the connecting-arms are freed, the two strips of metal referred to above prevent the door dropping and locking at this stage. When they are inserted beside the connecting-arms, the turned over length at the end stops the connecting-arms falling right down by catching against the roller supports (Fig. 4A). When the door is almost right open, the two strips, freed of the support of the rollers, fall, leaving the connecting-arms free to close to their fullest extent (Figs. 4B, I C). The two strips are each pivoted by a small bolt immediately in front of the vanes.

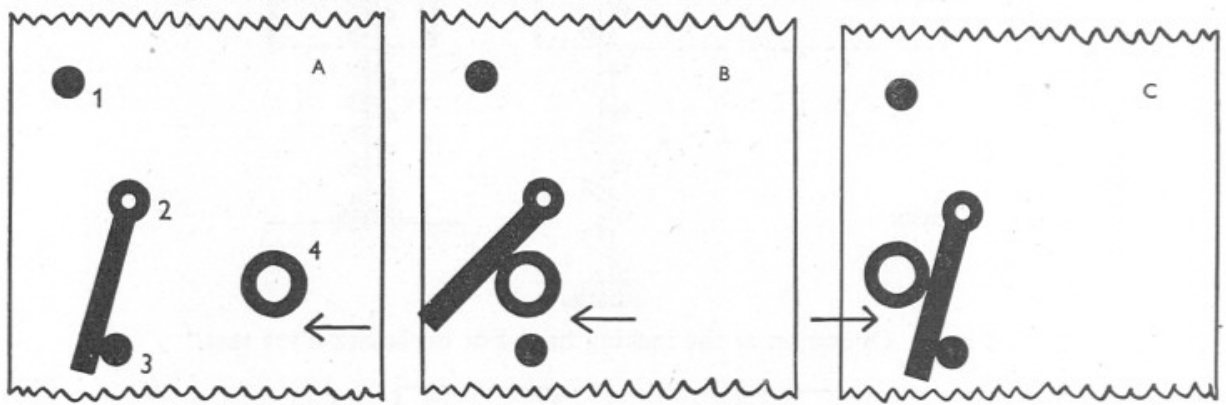

Fig. 5. Detail of trip locking mechanism. A, door nearly shut, the hinge pin is nearing the trip; $\mathrm{B}$, the hinge pin contacts the trip and pushes it up; $\mathrm{C}$, the hinge pin has passed outside the circumference described by the tip of the trip and the trip has fallen back against the locking bolt, preventing the return of the hinge pin. I, stopping bolt, to prevent the trip reversing; 2 , trip; 3 , locking bolt; 4 , lever/connecting-arm hinge pin. The arrow indicates the direction of movement of the hinge pin.

A stop-bolt in each connecting-arm, acting against the roller supports, prevents the door from going beyond the fully open position (Fig. 4B, $s$ ).

It will be appreciated that when the door is in the open position, each roller acts as a fulcrum (Fig. 2 $\mathrm{B}, f$ ), each connecting-arm a lever with a weight at one end, the vanes (Fig. 2B, wI), and a weight at the other end, the door trying to close (Fig. 2 B, w2). It is very important that these weights should be so disposed that, in the fully open position, the weight of the vanes is only very slightly less than that of the door. If this is done, only the minimum of pressure is necessary to maintain the door fully open and steady.

During experiments in an open-air swimming bath, it was found that the door remained quite steadily open at speeds of less than $\frac{1}{2}$ m.p.h., or about $35 \mathrm{ft}$./min. This is important since it means that the door will remain fully and steadily open regardless of any irregularities in the towing speed, providing that the speed does not fall below this very low minimum. 
When the net has finished its haul, it is stopped, causing the door to fall and engage three locking trips, one at the bottom centre of the door, and one at each lever/connecting-arm hinge (Fig. IB), in the manner shown in Fig. $5 \mathrm{~A}-\mathrm{C}$. The projecting lever/connecting-arm hinge pins engage the two outside trips, which are attached to the inside of the uprights of the anterior net-box support.

The importance of having the door bolted behind the door hinge is shown here, since this helps the door to fall beyond the vertical position, so that when the net is being hauled in, water pressure causes the door to be pushed back against the trips and held locked in a vertical position.

\section{SHOOTING}

The net can be shot by manhandling it over the side, but it is much more convenient to use a block and tackle. The method now adopted is as follows. The main warp from the winch is attached to the bridles via a ball-bearing swivel. A rope with a hook at the end is passed over a pulley attached to the mizzen boom. The rope is hooked to one of the swivel links. By means of this rope the net is lifted and swung outboard and lowered clear of the ship's side until the main warp takes the strain. This is to make sure that the small halfrunners do not touch the side of the ship, thus releasing the connecting-arms. It is then a simple matter to lean over the side and detach the hook. The net is now lowered until it is some ro or $20 \mathrm{ft}$. below the surface. For the above operations the ship is stationary. The ship now gets under way at tow-net speed. The net is observed to ensure that it is trailing the right way up, and is lowered. It is lowered quickly at first, but when it gets near the bottom, the warp is let out at about half the rate at which the ship is moving, until the necessary length of warp is out. The ship continues under way until the haul is finished, when a length of some $20 \mathrm{ft}$. of warp is let out as quickly as possible. This brings the net to a halt and enables the door to close and lock. The ship then heaves to and the net is hauled in. When the swivel is within reach, the rope is hooked on to it, and the last few feet of hauling is done by this. After the bucket has been detached, the net is unlocked and set for the next haul.

There has never been any difficulty in getting the apparatus to land the right way up. This is ensured by the low centre of gravity, the ball-bearing swivel, and having the towing shackles placed about a foot back from the front of the apparatus, near the point of balance, which corresponds with the third cross-bar (Fig. I C). When being let out, the warp is at about $45^{\circ}$ and the net is only about $15^{\circ}$ out of horizontal.

The time taken for shooting is about $30 \mathrm{sec}$. 


\section{Discussion}

From the outset it was decided that the design must be simple, effective, and self-contained, dispensing with messengers and throttling nooses. As can be seen from the description, all the working attachments are extremely simple, having no intricate mechanisms which may fail to function or function wrongly. Throughout the construction of the apparatus precise workmanship was never needed, and indeed, would have been a waste of time. The cost of construction is therefore very low.

The only part where any particular care is needed is in getting the right balance between the weight of the vanes and the weight of the door when in a fully open position, as described above.

The size of the aperture is a matter of choice for the maker; but the vane area must be increased or decreased accordingly. In the small model already mentioned, the optimum area of the vanes was found experimentally from tests with varying-sized vanes in the open-air swimming bath, where the results could be clearly seen. The vanes were then detached, and a length of cord was attached to the ends of the connecting-arms. This was led over a pulley and attached to various weights until the weight on the cord was sufficient to pull the door fully open. Knowing the area of the vanes, it was possible to calculate what weight of door would be opened by a certain area of vane. Then, by finding the weight necessary to open the door of the big net, the area of the vanes to be used could be worked out. The figure arrived at was $5 \frac{1}{2}$ sq.in. for every ounce of weight (approx.). Of course, the pressure of water against the door itself will tend to open it, and this has to be taken into consideration, but the figure arrived at offers a good maximal startingpoint.

The opening and shutting of the door rely upon two ever-present factors, i.e. water pressure and gravity. Because of this, the net can be operated on any type of workable bottom.

For quantitative work, hauls can be made of a specified duration since the net can be closed while it is still on the bottom.

There are no obstructions in front of the aperture of the net.

The apparatus can be used in quite rough weather.

All parts, except the lever/connecting-arm hinges, are protected by being within the area of the base frame. The lever/connecting-arm hinges are protected by 'bumpers' (Fig. I B).

Different metals are, as far as is possible, prevented from coming into contact by an application of bituminous paint.

In Fig. I в \& C two attachments can be seen on the back cross-bar. To these can be fitted, when required, a small, coarse-silk net about 9 in. square. The purpose of this is to catch the small members of the benthic fauna which are disturbed by the runners. These are caught in the vortices 
behind the right-hand vane and so are swept into the net. Small as the net is, it is surprising the numbers of animals that it catches, e.g. Amphipoda, Cumacea, etc.

\section{SUMMARY}

A description is given of a new type of apparatus designed to sample plankton from the immediate vicinity of the sea bottom, and purely from this region. Details of the construction are given and the relative merits of the design are briefly discussed.

It could be used for quantitative hauls.

A small additional net serves to sample the smaller benthic fauna at the same time as bottom plankton is being sampled.

\section{REFERENCES}

BeAuchamp, R. S. A., 1932. A new dredge. Intern. Rev. ges. Hydrobiol. Hydrog., Bd. 27, pp. 467-9.

BosSANYI, J., I95I. An apparatus for the collection of plankton in the immediate vicinity of the sea-bottom. Fourn. Mar. Biol. Assoc., Vol. 30, pp. 265-70.

Giesbrecht, W., I893. Ein neues Schliessnetz. Mitth. Zool. Station Neapel, Bd. II, pp. 306-24.

GREZE, V. N., I95I. Bottom plankton, its role in the nutrition of fish, and methods of its evaluation. Zoologicheskii Zhurnal, Vol. 39, Part I, pp. 44-50. (In Russian.)

Hensen, V., I895. Methodik der Untersuchungen. Ergebnisse der Plankton-Expedition der Humboldt-Stiftung, Bd. I, B., 200 pp.

REIGHARD, J. E., I894. Some plankton studies in the Great Lakes. Bull. U.S. Fish Comm., for 1893, pp. I27-42.

RusSell, F. S., 1928. A net for catching plankton near the bottom. Fourn. Mar. Biol. Assoc., Vol. 15, pp. 105-8. 